\title{
Fallen Angels and Price Pressure
}

June 2, 2009

\author{
Brent W. Ambrose \\ Smeal Professor of Real Estate \\ Director, Institute for Real Estate Studies \\ Smeal College of Business \\ Penn State University \\ University Park, PA 16802 \\ email: bwa10@psu.edu
}

\author{
Kelly N. Cai \\ Assistant Professor \\ Department of Accounting and Finance \\ University of Michigan - Dearborn \\ 19000 Hubbard Dr. \\ Dearborn, MI 48126-2638 \\ email: kcai@umd.umich.edu \\ and \\ Jean Helwege \\ Associate Professor \\ Department of Finance \\ Smeal College of Business \\ Penn State University \\ University Park, PA 16802 \\ email: juh20@psu.edu.
}

We are grateful for helpful comments from Laura Field, Steve Mann and Marco Rossi. Marco Rossi and Yuan Wang provided excellent research assistance. This work was sponsored in part by a research grant from the Smeal College of Business. 


\section{Fallen Angels and Price Pressure}

Previous empirical research has attempted to quantify the extent of price pressure when major quantities of a security are sold or bought, but most studies suffer from the fact that the unusually large sales or purchases involve information effects as well. We examine forced selling of fallen angel bonds by insurance companies to estimate price pressure effects. We restrict our sample of downgraded bonds to include only firms whose stock has no significant reaction to the downgrade, making the sale of these fallen angels far more likely to merely represent regulatory pressure to dispose of junk bonds. Once we control for information, we find that price pressure effects are negligible, if not non-existent. To the extent that any price pressure effects show up in these bond sales, they ought to be greater for illiquid bonds. We do not find that bond liquidity explains the variation in bond returns in our information-free sample, further supporting our contention that price pressure is not a major factor in security pricing.

Key Words: price pressure, liquidity, fallen angel bonds, insurance companies

JEL: G10, G12 
Standard asset pricing models do not admit a role for price pressure, which is the impact on returns that arises from the act of selling or buying a large quantity of a particular security. According to the CAPM, for example, the security is completely defined by its risk characteristics, so stocks of a given risk class are perfectly interchangeable and there are no shortages or excesses of the risk class. More recent analysis, however, has highlighted the role of liquidity in security returns, suggesting that liquidity is priced. ${ }^{1}$ While the definition of liquidity is difficult to pin down, let alone measure with confidence, a reasonably liquid security is one that can be easily bought and sold. Perhaps no security is so liquid that a large quantity can be traded without impacting its price, but undoubtedly an illiquid security is one that suffers greatly from price pressure, even when the quantity traded is not very large.

The extent to which price pressure affects returns is an empirical question of great interest but is extremely challenging to answer. Early research on the topic focuses on large sales of stock, including the seminal paper by Scholes (1972) who investigates block sales. However, these events are not completely devoid of information and thus one is at a loss to determine how much of the stock price decline reflects information effects and how much is due to the act of trading. ${ }^{2}$ Other attempts to document the impact of the act of trading include a large literature on additions to stock indexes, such as the S\&P 500 index (Shleifer (1986), Harris and Gurel (1986) and Wurgler and Zhuravskaya (2002)). Again, researchers now doubt the extent to which inclusion in an

\footnotetext{
${ }^{1}$ See Acharya and Pedersen (2005), Jacoby, Fowler and Gottesman (2000) and Sadka (2006).

${ }^{2}$ Related papers on block trades, secondary and seasoned offerings, and IPO lock-up expirations include Mikkelson and Partch (1985), Keim and Madhavan (1998), Clarke, Dunbar and Kahle (2004), Field and Hanka (2001), Corwin (2003), Ofek and Richardson (2000) and Schultz (2006).
} 
index is an event that is free of information effects. ${ }^{3}$ Mitchell, Pulvino, and Stafford (2002) examine selling pressure in cases of merger arbitrage, D’Mello, Ferris and Hwang (2003) examine tax loss selling at the turn of the year, and Coval and Stafford (2007) examine mutual fund flows. However, rarely can we be confident that the price pressure effects measured in these studies are truly devoid of information.

In this study we take advantage of a situation where trading occurs because of regulatory pressure and where information effects are small to nonexistent because they occur before the period when regulations come into force. Our study investigates the impact of price pressure using a sample of fallen angel bonds, which are bonds that no longer carry an investment grade rating. Although downgrades on average are informative events, in many cases the rating action occurs well after the bad news about the firm has become public information. We restrict our sample of fallen angel bonds to cases where the information in the rating downgrade has been incorporated into bond prices well in advance of the downgrade. Thus, the selling in our situation reflects insurance companies’ responses to regulatory pressure to unload bonds that are no longer suitable for the portfolio. We show that selling pressure is widespread for these fallen angels; we calculate the average price decline when bonds are sold; and we show the extent to which the more illiquid bonds suffer from greater price pressure.

We restrict our analysis to insurance companies for two reasons: First, due to portfolio holdings regulations and risk-based capital regulations, they are highly likely to sell corporate bonds that are downgraded to junk status; second, unlike other regulated fixed income investors, their transactions are easily identified because they are required

\footnotetext{
${ }^{3}$ See Denis, McConnel, Ovtchinnikov and Yu (2003). Kaul, Mohrota, and Morck (2000) consider reweighting of an index to avoid such information effects.
} 
to report daily data on corporate bond transactions to the National Association of Insurance Commissioners (NAIC). Our study works best if insurance companies buy investment grade bonds that are likely to become fallen angels (as opposed, say, to only the highest category of investment grade bonds) and if they are forced to sell them once they become fallen angels. Evidence in Cai, Helwege, and Warga (2007) indicates that insurers do indeed purchase a wide variety of investment-grade bonds, while data presented by Ambrose, Cai, Helwege (2008) (henceforth, ACH) indicates that insurance companies subsequently sell a large number of fallen angels once the downgrade occurs.

Another element of our study that is critical to the success of the experiment is the existence of a large number of fallen angel downgrades that do not convey information to the market. Prior research has shown that stocks do not react much to bond rating changes (e.g., Hand, Holthausen and Leftwich (1992)). This likely owes to the market incorporating the negative information into stock prices well in advance of the actual downgrade. This suggests that, at least in some cases, the information content of a bond downgrade is incorporated into bond prices well in advance of an actual rating change. Nonetheless, the stock market reaction to bond downgrades is significantly negative on average, indicating that we cannot assume all fallen angel downgrades constitute a "nonevent.” Yet, within the substantial number of downgrades to junk levels, a sizeable fraction does not elicit a significant stock price reaction. For this subset of fallen angels, we believe that the downgrade to fallen angel status is largely devoid of information and therefore presents an opportunity to study price pressure from forced selling. Using similar data, Ellul, Jotikasthira and Lundblad (2009) study the returns of all fallen angels 
and find significant price drops. We attribute their findings largely to the effects of information.

We investigate the price pressure hypothesis with NAIC data during the period 1995-2006. To compute price pressure returns, ideally, we would observe prices the day before the downgrade and then again right after the downgrade, but because corporate bonds do not trade often, we have limited ability to investigate the impact of price pressure on returns. We use a wider window to calculate price pressure returns and consider trades within two weeks of the downgrade (up to two weeks before the event date to no more than two weeks after) as well as trades within 100 calendar days of the downgrade. Using a two-week window and restricting the sample to cases where information effects are minimal, we find that the average bond price decline is an insignificant 0.45 percent $(0.07$ percent if returns are adjusted for the corporate bond market index). In comparison, fallen angel bonds belonging to firms whose stock price reacted negatively to the rating change experience a significant -10.19 percent price decline on average (-10.84 percent if returns are adjusted for the corporate bond market index). The difference in returns between these groups is significant, suggesting that information effects dominate price declines and price pressure effects are negligible. Further, we relate this estimated price pressure to measures of bond market liquidity and find that our proxies for liquidity are not significantly related to bond returns. Thus, our analysis suggests price pressure likely has only a small role - perhaps no impact whatsoever - in the drop in prices when massive selling occurs. Rather, the drop in prices so often observed in the market reflects a change in fundamentals. 
The remainder of the paper is organized as follows: Section 2 discusses the method for calculating bond returns and our procedure for identifying information-free events and the effects of liquidity. Section 3 describes our data, and section 4 presents the results. Section 5 is the conclusion.

\section{Methodology}

Our study begins with a group of firms whose bonds have been downgraded from investment grade to speculative grade during a period for which insurance company bond trades are available. Insurance companies face restrictions on the amount of speculative grade debt they may hold as well as harsher capital requirements on the portion of their portfolio held in the form of junk bonds. Thus, insurers face strong regulatory pressure to sell the bond and limit the amount of junk bonds in the portfolio when bonds become fallen angels. ACH show that insurance company sales of fallen angel bonds are orders of magnitude higher than sales of similar bonds.

If price pressure effects exist, we expect to see the prices of the fallen angel bonds drop from before to after the downgrade as a result of this selling pressure. We could examine the change in price by looking at the changes in sell transaction prices, the changes in buy transaction prices, or the changes in other transactions (mixtures of buy and sell prices). Theory predicts that price pressure will affect the security through one or both of two channels: the fundamental (unobserved) price will drop and/or the bid-ask spread will widen. Presumably the latter will take place through reduced bid prices in sell transactions, not higher offer prices in buy transactions. Thus, if price pressure affects prices through both channels the return calculated using only sell transactions will 
reflect the total drop due to price pressure whereas using only buy transactions will understate the effects by ignoring the wider bid-ask spread. Using a combination of buy and sell transactions is problematic because it is difficult to measure the bid-ask spread on bonds (it requires both a buy and sell transaction on the same day, which is rare), but even harder to measure the correct post-downgrade spread. That is, the bid-ask spread ought to widen even if there are no price pressures because the fallen angel bonds are now junk and junk bonds trade at a wider bid-ask spread than investment grade bonds (see Hong and Warga (2000)). Therefore, we restrict our analysis to sell transactions, and test for price pressure using bond returns based on sales.

\section{A. Measuring bond returns}

In order to focus on regulatory price pressure, we restrict our analysis to bonds with trades in the 100 day period before and after the downgrade event. ${ }^{4}$ More specifically, we require each issue to have at least one trade in the "before period" and one trade in the "after period." Denote the downgrade date as day 0 . The "before period" is from 100 days before the downgrade date to the day before the downgrade date $[-100,-1]$. The "after period" is from the downgrade date to 99 days after the downgrade date $[0,99]$. For issues with more than one trading day in the before (or after) period, we keep the trade that is closest to the downgrade date. For example, consider an issue with a downgrade date of February 1 and four sell transactions before the downgrade (January 24, January 27, January 29, and January 29), and three sell transactions after the downgrade date (February 4, February 7, and February 7.) For the before period, we only

\footnotetext{
${ }^{4}$ As noted in ACH, the majority of fallen angels have no sell transactions by insurance companies in the month following the downgrade.
} 
keep the trades on January 29 and for the after period, we only keep the trade on February

4.

For issues with more than one trade in a day (as on January 29 in the above example), we use all the information by creating a weighted average price. The weights are the fraction of the day's total transactions accounted for by each trade. In the above example, for trades on January 29, we calculate the weighted average total price and denote January 29 as the "before date.” Similarly, we denote the trading date after the downgrade date as the "after date” (in the example above, February 4).

In order to calculate the bond return during the downgrade period, we require that each issue have trades on the "before date" and "after date". We use the (weighted average) total price on the "before date" $\left(P_{f}^{\text {Before }}\right)$ and the (weighted average) total price on the "after date" $\left(P_{f}^{A f t e r}\right)$ to compute the return. Since this return reflects the price change, we refer to it as the "total raw return" $\left(B R_{i, n}\right)$ and is calculated as:

$$
B R_{i, n}=\frac{P_{f}^{A f t e r}-P_{f}^{\text {Before }}}{P_{f}^{\text {Before }}}
$$

where $n$ is the number of days between the two dates.

Since the "before date" and "after date" is on average more than 50 days apart, we also construct a return measure to correct for possible changes in the bond market during this window. We use the Lehman Brothers US Corporate Index and the Lehman Brothers High Yield Index ${ }^{5}$ as benchmark measures of the market. ${ }^{6}$ These indexes

\footnotetext{
${ }^{5}$ Source: Lehman Brothers Global Family of Indices. Copyright 2008. Used with permission.

${ }^{6}$ These indices include all publicly traded U.S. corporate debentures and secured notes that meet prescribed maturity, liquidity, and quality guidelines. Securities with calls, puts and sinking fund provisions are included, which is standard for indices. However, the indices exclude private placements, 144A securities, floating rate securities, and Eurobonds. In addition, the SG index excludes pay-in-kind bonds and debt
} 
provide daily return data for investment grade bonds starting in April 1996, and in August 1998 for high yield bonds. The index is categorized into the following 16 subindices based on respective maturities and credit risk: Investment grade (A intermediate daily, A long daily, AA intermediate daily, AA long daily, AAA intermediate daily, AAA long daily, BAA intermediate daily and BAA long daily) and High yield grade (B intermediate daily, B long daily, BB intermediate daily, BB long daily, CAA intermediate daily, CAA long daily, CA-D intermediate daily and CA-D long daily).

To calculate market-adjusted returns, we match each bond to one of the indices based on maturity and rating and then subtract the bond index return from the bond's total raw return. ${ }^{7}$

The market-adjusted return is calculated as:

$$
\operatorname{MARK}_{i, n}=B R_{i, n}-\prod_{j=1}^{n} I N D X_{i, t-n+j}
$$

where $B R_{i, n}$ is the total raw return on bond $i$ over $n$ days from "before date" to "after date” calculated from equation (1) and $\prod_{j=1}^{n} I N D X_{i, t-n+j}$ is the cumulative index return over the $n$ days starting on the "before date" for the bond index with the same rating and similar maturity. Since the issues in our sample are downgraded from investment grade to high yield grade on the downgrade date, we use the corresponding Lehman Brothers corporate index to obtain returns from the "before date" to one day before the downgrade date and use the corresponding Lehman Brothers High Yield index to obtain returns from the downgrade date to the "after date."

issues from countries designated as emerging markets. These indices are market value-weighted and inclusive of accrued interest.

${ }^{7}$ The Lehman indices use Moody’s ratings to classify high grade bonds, and S\&P ratings for junk issues.

For consistency, we convert all ratings into their equivalent S\&P categories. 
Continuing the previous example, if the bond issue was downgraded from rating $\mathrm{BBB}$ to $\mathrm{BB}$ on February 1 and the bond's time to maturity is five years, and the "before date" is January 29, the "after date” is February 4, and we compute $\prod_{j=1}^{n} I N D X_{i, t-n+j}$ using the daily returns from the Lehman Brothers Corporate rating BBB Intermediate index for the period January 29 to January 31 and the daily returns from Lehman Brothers High Yield rating BB Intermediate index for the period February 1 to February $4 .^{8}$

\section{B. Measuring information effects}

Previous studies of price pressure suffer from the problem that sell transactions often take place because the investor believes he has information indicating that future returns will be low. Our dataset allows us to evaluate the role of price pressure in a setting where there are no information effects because the sale takes place simply as a result of regulatory constraints. We do not argue, however, that all fallen angel downgrades are events that are free of information effects. Some of the downgrades are unexpected and cause investors to reduce their valuations of the securities. Others are expected but the downgrade is not as severe as some investors had anticipated, perversely leading to positive information effects on the announcement. In order to identify a sample of fallen angels with no information effects, we conduct an event study on the stock returns of the downgraded firm. A fallen angel whose stock has not changed as a result of the announcement is likely to have a bond return that only reflects price pressure effects.

\footnotetext{
${ }^{8}$ For part of the period covered in our analysis daily data is not available, and thus, we use monthly data and assume a constant daily return over the month.
} 
We cannot exactly employ the standard event study method because we wish to know whether the stock market reaction to the downgrade is significant for a single firm. As with other event studies, we start by estimating a single factor market model for each firm and then we use the estimated parameters to calculate the daily abnormal return $\left(A R_{i t}\right)$ on day $t$ for each firm during the event window as:

$$
A R_{i t}=r_{i t}-\left(\hat{\alpha}_{i}+\hat{\beta}_{i} r_{M t}\right)
$$

where $r_{i t}$ is the common stock return for firm $i$ on day $t, r_{M t}$ is the return on the market portfolio on day $t$, and $\hat{\alpha}_{i}$ and $\hat{\beta}_{i}$ are the coefficients estimated from the market model. We estimate the parameters in (3) using returns from day -120 to day -31 , where day 0 denotes the downgrade date. ${ }^{9}$ We next calculate the mean daily abnormal return over $[-1$, +1]. To determine if $\overline{A R_{i}}$ is significantly different from zero we need a standard deviation for the firm. We assume the excess return over our event window is drawn from the same distribution of excess returns observed over [-120,-31] and use the standard deviation estimated over that interval to conduct a t-test for the $[-1,+1]$ window. Due to sparse trading of bonds, later we further restrict the sample of information-free bonds identified with this t-test and widen the window to conduct another t-test of the same design.

For most bonds, a downgrade from investment grade to junk is viewed as a negative event. Thus, on average we expect the price to fall when the bond is downgraded, regardless of whether there is price pressure. In addition, if price pressure effects exist then the forced selling of fallen angels should reduce the price further. If we compare the firms for which the downgrade is not news (i.e., the stock does not react to

\footnotetext{
${ }^{9}$ We end the window for calculating excess returns one month before the downgrade date to avoid contamination due to extreme information effects.
} 
the announcement) to firms for which the downgrade is bad news, the latter should have a more negative return than the former (the ones for which the rating change is informative have a price pressure effect and a negative information effect, and if the two price pressure effects are the same on average then the added negative news effect will make the magnitude of the bond return larger for the informative downgrades). If the news about the downgrade is significantly positive, we would have offsetting effects and could not identify the price pressure effects. Therefore, we restrict our analysis to firms with no stock reaction and to those with negative stock reactions, eliminating the portion of the sample with positive stock reactions.

\section{Price pressure effects and liquidity}

To the extent that we find evidence of price pressure effects from forced selling of fallen angels, we expect the effects to be greater the less liquid the bond. Corporate bonds in general are considered illiquid instruments, so the downward pressure on prices as insurance companies sell fallen angel bonds should be greater when the security already has features that make it hard to find a buyer. Equity researchers often use the bid-ask spread, trading volume and the percentage of zero trading days as measures of liquidity. ${ }^{10}$ However, corporate bond trading is quite sparse so calculating a bid-ask spread is difficult (Hong and Warga (1998), Schultz (1998) and Chakravarty and Sarkar (1999)) and even more so for insurance companies that do not trade as frequently as other bond investors. Previous researchers in the area of corporate bonds therefore have identified three other measures of liquidity: issue size, age, and time to maturity (Crabbe and Turner (1995), Alexander, Edwards, Ferri (2000), and Hotchkiss and Jostova (2007)).

\footnotetext{
${ }^{10}$ See, for example, Demsetz (1968), Grossman and Miller (1987), Lesmond, Ogden and Trzcinka (1999).
} 


\section{Data}

Following ACH, we utilize the Fixed Income Securities Database (FISD) to identify the set of fallen angels used in our empirical analysis. FISD, provided by Mergent, Inc., contains detailed issuance and ratings information for all fixed income securities with CUSIP identifiers and maturity dates after 1990. In addition to FISD, Mergent provides data on fixed income security transactions by insurance companies that are reported to the NAIC from 1995. Although these trades do not constitute the entire population of participants in the U.S. corporate bond market, Campbell and Taksler (2003) and Hong and Warga (2000) note that the NAIC data accounts for a large volume of the overall market (approximately one third of all corporate bonds) and is more representative of the typical corporate bond market transaction than transactions completed on the NYSE's Automated Bond System. In addition, as ACH point out, the NAIC data cover trades by institutions most likely to face regulatory pressure to sell bonds.

Our dataset includes all fallen angels from 1995-2006 that are straight debentures or medium term notes. We exclude from the analysis convertible and zero coupon bonds, retail notes, asset-backed securities, trust preferred capital securities, Yankee bonds, Canadian bonds, and bonds denominated in non-U.S. currencies (as bankruptcy laws in other countries may affect insurance company investment decisions when these bonds approach distress). In order to focus on the most liquid bonds, we delete all bonds with offering amounts less than \$5 million. Finally, we require all bonds in the dataset to have information on the issue offering amount, offer date, industry group, and bond type. Based on these screens, our dataset contains 49,012 individual bond issues. ACH provide 
detailed tables describing the characteristics of bonds in the dataset and their trading activity.

During our sample period, Moody’s Investors Service (Moody's), Standard \& Poor’s (S\&P), Fitch Investors Service (Fitch), and Duff \& Phelps Credit Rating Agency (DCR) may have assigned ratings to the bonds in our sample. As a result, a number of potential scenarios arise for a bond issue to become a fallen angel. First, as Moody's and S\&P are the larger and more important of the four rating agencies, fallen angel status should reflect changes in bond ratings from either of these agencies. In other words, we define a fallen angel as a bond that once had an investment grade rating from Moody's or S\&P (not necessarily both) and was downgraded such that it no longer had an investment grade rating from either. For the purposes of our study on price pressure, the date that the bond became a fallen angel from either agency is the "event" date. Using changes in Moody's and S\&P ratings, we identify 1,836 fallen angel bonds in our sample.

Alternatively, we also note that insurance company regulations often consider all available ratings. As a result, a bond could still be classified as investment grade if either Fitch or DCR still maintain an investment grade rating even though Moody's and S\&P rate the bond as junk. In order to control for this possibility, we also examine price pressure based on the alternative definition of a fallen angel as a bond that once had an investment grade rating from at least one of the four rating agencies and no longer has an investment grade rating from any of the four. ${ }^{11}$ Based on the more restrictive definition using the four rating agencies, we identify 1,191 fallen angel bond issues. ACH report that the volume of forced selling appears to be about the same regardless of which set of

\footnotetext{
${ }^{11}$ In April 2000, Fitch acquired DCR. Consequently, we use only three ratings in the latter half of our sample, but four in the first half.
} 
ratings is used to define a fallen angel, which likely reflects the fact that the downgrades from all agencies tend to come around the same time. While Moody's and S\&P are decidedly the more important of the four rating agencies, we believe the loss of the last investment grade rating is the most important determinant of whether the bond is sold in response to regulatory pressures. Thus, empirical results using four agencies are likely to be more reliable.

As noted above, the number of fallen angels is a relatively small set of the universe of corporate bonds. Using the four agency definition, we note that fallen angels represent 2.4 percent of the 49,012 bonds meeting the data screens for initial inclusion in our study. Furthermore, bonds do not trade frequently. For example, using the NAIC database, Hotchkiss and Jostova (2007) report that 79.4 percent of the bonds have no trades over the entire five year period of their study. Moreover, buy transactions outnumber sell transactions in four of the five years and therefore in the sample as a whole. ACH report that bonds are sold on average less than once a month (the average is 0.21 sales transactions per month). This makes any study of bond returns problematic, because in many instances researchers are unable to obtain the minimum two prices necessary to calculate a return.

While the level of trading in corporate bond markets is typically quite low, downgrades from investment grade to junk trigger a surge in trading activity, especially selling by regulated entities. In response to regulatory pressures, insurance companies sell fallen angels at a sharply higher rate than other bonds: ACH report a rate of 1.5 sell transactions per month. This is several orders of magnitude higher than the 0.21 sell 
transactions per month in the sample overall and it is statistically significantly greater than the 0.04 monthly sales transactions of their matched sample. ${ }^{12}$

Any reliable analysis of price pressure effects requires that the fallen angel bonds trade both before and after the downgrade in order to calculate a return. ${ }^{13}$ This limits the sample considerably. Table I details the number of buy and sell transactions within 100 calendar days of the downgrade event date for our sample of fallen angel bonds (Panel A shows trades for the fallen angels defined with two rating agencies and Panel B shows the data based on four rating agencies.) For example, Panel B shows that only 58 percent $(686 / 1,191)$ of the fallen angels defined by the four agencies have any selling activity by insurance companies in the 100 calendar days following the downgrade. Even fewer, only 51 percent $(613 / 1,191)$, have at least one sell transaction during the 100 days prior to the downgrade event. Note that buying volume is even smaller, reflecting the fact that many insurance companies shun these bonds once they reach junk levels and others sell the bonds in advance of the official downgrade.

Next we examine the stock market reaction to the announcement of the bond downgrade. Of the 1,836 fallen angels (1,191 based on four agencies), 438 (235) do not have stock prices on CRSP (reflecting the presence of private firms and bonds issued by subsidiaries whose parents are not readily identified by the CUSIP) and 78 (128) have significant positive stock returns over the three-day window (reflecting the fact that the downgrade was not as harsh as expected or downgrades due to pro-equity actions such as

\footnotetext{
${ }^{12} \mathrm{ACH}$ show that sales diminish as bonds age and as credit quality increases, factors that have offsetting effects with fallen angels (which are typically older bonds). Thus it is important to hold constant features of the bond when considering the significance of changes in trading activity.

${ }^{13}$ Ellul, Jotikasthira and Lundblad (2009) estimate a model of all fallen angels to determine a predicted (matrix) price so that only one trade is needed for a bond to be included in the analysis. In essence this approach imposes the restriction that all fallen angels experience the same price effects as a result of the downgrade.
} 
leveraged buyouts). This leaves 1,320 (828 using four agencies) bonds with either negative information effects (401/245) or no information effects (919/583). However, not all of these bonds trade often enough over the $[-100,+99]$ window to calculate a return: 384 (263) bonds with no stock market reaction have at least one sell trade on each side of the downgrade date in the dataset and 133 (100) bonds with negative stock reactions have at least one sell transaction on each side of the downgrade date.

\section{Results}

We begin our analysis of bond returns with the largest sample that we obtain by using an event window that spans -100 to +99 days around the downgrade date. We analyze this sample mainly to illustrate the effects of information, which are quite negative. Table II reports the cumulative raw and excess (index-adjusted) returns for the fallen angels that have at least one sell transaction on each side of the downgrade date. The table reports the returns using fallen angel samples identified based on the two rating agencies (Moody's and S\&P) and the four rating agencies. In Panel A, we see that out of the 1,836 fallen angels identified using Moody’s and S\&P, 517 bonds with non-positive stock effects (384 bonds with no stock market reaction and 133 bonds with negative stock reactions) had at least one sell transaction in the 100 days before the downgrade and another one in the 100 days following the downgrade. Of the 1,191 fallen angels identified using the more relevant four rating agency criteria, 363 (263 bonds with no stock market reaction and 100 bonds with negative stock reactions) meet the requirements during the event window. 
Panel A shows that the mean cumulative raw return $\left(B R_{t, n}\right)$ for the group of firms that have significant negative stock price reactions to the downgrade is quite negative: -12.60 percent using two ratings agencies and -13.90 percent based on four agencies. Both returns are statistically different from zero at the 1 percent level. Recall that these negative returns reflect two effects: the price pressure effect and information effects as investors learn the bad news that triggered the downgrade. In comparison, $B R_{t, n}$ is only -3.79 percent (two agencies) or -3.11 percent (four agencies) for the group of firms where the downgrade contained no information to stockholders. Both returns are statistically different from zero at the 1 percent level. The t-statistic for the difference in the means across the two groups is statistically significant regardless of the number of rating agencies involved, implying that the bond returns for the negative stock return group are worse because they contain both information and price pressure effects while the bonds in the zero stock return group are only affected by price pressure.

We see a similar pattern when the cumulative returns are adjusted for the change in the relevant bond index $\left(M A R K_{i, n}\right)$. The excess bond return over the 100-day event window is sharply negative for the group with information effects $(-13.72$ percent using two agencies and -15.27 percent for the four-agency sample) while the information-free bond sample only drops in value by about half as much (-7.60 percent and -6.94 percent for the two-agency and four-agency samples, respectively). While both samples have significantly negative returns, again the t-statistics for the differences in means indicate that the zero stock return group’s bond suffer less because they only experience price pressure and not information effects. 
However, before concluding that the significant negative returns for the zero stock return group in Panel A support the price pressure hypothesis, we note that our supposedly information-free bond returns probably have some negative information effects in them because the stock return window is only three days while the bond return window is potentially much longer. Specifically, in Panel A we estimate the information content from the stock returns using the window $[-1,+1]$ but we calculate bond returns over a much longer event window, possibly as long as $[-100,+99]$. In order to reduce the potential bias resulting from this difference in return windows we redo the analysis using a narrower window for the bond returns.

In Panel B we report bond returns using a two week $[-14,+13]$ window on either side of the downgrade date. Reflecting the sparseness of corporate bond trading, only about a quarter of the bonds analyzed in Panel A trade twice within this calendar month. The average number of days between trades is a bit more than six for the firms with information effects and closer to 11 for the firms with insignificant stock price reactions to the downgrade. Thus, trading is even sparser when there is no news.

Adjusted returns $\left(M A R K_{i, n}\right)$ for firms with information effects are somewhat smaller in magnitude in Panel B than in Panel A. For example, in the four-agency sample, $M A R K_{i, n}$ is -10.84 percent when the event window is restricted to be within two weeks of the downgrade while it is -15.27 percent over the 100-day event window. However, the point estimate for the firms with no stock market reaction is sharply lower, regardless of whether one defines fallen angels with two agencies (-1.50 percent) or four agencies (0.45 percent). The t-statistics for the negative stock return group suggest a strong information effect (-2.76 or -2.69 depending on the rating agencies used) but the t- 
statistics for the zero stock return group are only statistically different from zero when using two agencies. Indeed, based on the more reliable four agency test, the point estimate for the market-adjusted returns is less than half of one percent and is not statistically different from zero ( $\mathrm{t}=-0.67)$. Because the information-free bonds' returns are significantly different from those of the negative information group, Panel B suggests that information effects are a large component of the negative bond returns associated with bond downgrades and the price pressure effects are small, and possibly do not exist. While the estimates in Panel B are much less likely to reflect information effects for the zero-stock return group than those reported in Panel A, we can further refine our tests to ensure that information effects are truly gone from the estimates of price pressure effects. In addition to requiring that there be no significant reaction in the stock market over $[-1,+1]$, we also require that the "Zero Abnormal Stock Return” firms do not have a significant abnormal stock return from the "before_date" to the "after_date" used in calculating the bond return. This additional restriction reduces the "Zero Abnormal Stock Return” group to 59 firms (from 80) in the two agency fallen angel sample and to 37 firms (from 60) in the four agency fallen angel sample. Again we find that the bond returns for the information-free cases are smaller in magnitude than those involving negative reactions in the stock market, and in this case the estimated price pressure effects are even smaller. Panel C again reports a difference in the market-adjusted means for two groups that is statistically different from zero. Further, the four agency downgrade cases are not significantly different from zero (as was the case in Panel B). We therefore conclude that the majority of the price reaction in the case of fallen angels 
reflects negative information and price pressures are negligible in magnitude, if not exactly zero.

Although our results suggest a small role for price pressure effects, the significant t-statistics for the two-agency sample may merely reflect information effects that are not apparent in the stock market. In order to further test for the existence of price pressure effects, we investigate whether the small negative returns that do exist in the informationfree sample are related to liquidity. If price pressure is really driving these returns, the negative bond returns ought to be observed among the least liquid bonds. We next examine whether various measures of bond liquidity can explain the negative price reactions.

Table III reports summary statistics on liquidity proxies for the bonds in the restricted no-information group and the negative information group that trade within 14 days of the downgrade date. We report measures of trading activity for the bond over a window $[-120,-31]$ that should be representative of the normal liquidity of the bond (before the downgrade event spurs abnormally high selling). Most bonds do not trade much, as can be seen by the high fraction of zero volume days, the low average number of trades and the rather small total trading volume. For example, in the four-agency sample the bonds in the negative information group typically experience no trading volume on 90 percent of the days analyzed while the typical bond with no information effects has no trading about as often. When trades do occur, the two groups have similarly low levels of trading prior to the downgrade. ${ }^{14}$ Neither set of firms has sufficient data to reliably estimate the bid-ask spread, as most bonds do not have a buy

\footnotetext{
${ }^{14}$ We also examine trading volume in TRACE (not reported) and find low levels of trading. However, because TRACE coverage starts well after the start of our sample period, our sample size is further curtailed using these measures of liquidity.
} 
and a sell transaction on the same date within our timeframe. We also calculate the average offering amount, bond age at downgrade, and time-to-maturity at downgrade as proxies for bond liquidity. The t-statistics testing for the differences in means are not significant suggesting that no observable differences in liquidity exist between the groups.

To systematically determine whether the minimal evidence in favor of price pressure truly reflects the difficulty of selling these fallen angels, we use the bond returns for the restricted no-information group and estimate the following OLS regression model:

$$
M A R K_{i, n}=\alpha+\beta^{\prime} L I Q_{i, n}+\varepsilon_{i}
$$

where $L I Q_{i, n}$ represent the various proxies for liquidity: percent of zero volume days, total dollar trading volume, total number of trades, issue size, age and time-to-maturity. Table IV presents the estimated coefficients. We see that the estimated parameters for the various liquidity measures are not reliably significant. While the percent of no trading days, the total number of trades and bond age are significant with the expected signs in the sample based on two rating agencies (Panel A), they are no longer significant when the sample is restricted to the more reliable four-agency approach (Panel B).

Furthermore, even when some variables are significant, the $\mathrm{R}^{2}$ values for the regressions are very low indicating that the liquidity parameters have almost no explanatory power. Thus, the results from OLS regression models reinforce our conclusion that negative bond returns associated with fallen angels do not reflect price pressure from forced sales. 


\section{Conclusion}

The existence of price pressure, the impact on returns that arises from the act of selling or buying a large quantity of a security, is controversial within the finance literature. For example, in the standard CAPM framework a security price is a function of its risk characteristics and thus leaves no role for price pressure to impact the security price. However, more recent studies have suggested that liquidity does impact security returns, thus opening an avenue for price pressure to affect security prices. In this paper, we explore the question of whether price pressure exists by exploiting a situation where trading occurs because of regulatory price pressure and information effects are minimal. Specifically, we test for price pressure using sales by insurance companies for a sample

of fallen angel bonds. Insurance companies face regulatory pressure to sell bonds that no longer carry investment grade ratings, thus providing an opportunity to separate the information effect from potential price pressure.

We separate fallen angels into two groups, those where the downgrade was most likely to have conveyed information as evidenced by a negative stock price reaction surrounding the downgrade event and those where the downgrade was uninformative. Examining bond returns surrounding the downgrade event for each group reveals little evidence for regulatory price pressure effects. Our analysis of the returns suggests most of the drop in prices owes to information effects and very little, if any, reflects price pressure. Further support for our conclusion that price pressures do not exist is the fact that the returns are not reliably related to measures of liquidity. 


\section{References}

Acharya, Viral V. and Lasse H. Pedersen, 2005, Asset pricing with liquidity risk, Journal of Financial Economics 77, 375-410.

Alexander, Gordon J., Amy K. Edwards, and Michael G. Ferri, 2000, The determinants of trading volume, Journal of Financial Markets 3, 177-204.

Ambrose, Brent W., Nianyun (Kelly) Cai and Jean Helwege, 2008, Forced selling of fallen angels, Journal of Fixed Income 18, 72-85.

Cai, Nianyun (Kelly), Jean Helwege and Arthur Warga, 2007, Underpricing in the corporate bond market, Review of Financial Studies 20, 2022-2046.

Campbell, John Y. and Glen B. Taksler, 2003, Equity volatility and corporate bond yields, Journal of Finance 58, 2321-2349.

Chakravarty, Sugato and Asani Sarkar, 2003, A comparison of trading costs in the U.S. corporate, municipal and Treasury bond markets, Journal of Fixed Income 13, 39-48.

Clarke, Jonathan, Craig Dunbar, and Kathleen Kahle, 2004, The long-run performance of secondary equity issues: A test of the windows of opportunity hypothesis, Journal of Business 77, 575-603.

Coval, Joshua and Erik Stafford, 2007, Asset fire sales (and purchases) in equity markets, Journal of Financial Economics 86, 479-512.

Corwin, Shane A., 2003, The determinants of underpricing for seasoned equity offers, Journal of Finance 58, 2249-2279.

Crabbe, Leland E. and Christopher M. Turner, 1995, Does the liquidity of a debt issue increase with its size? Evidence from the corporate bond and medium-term note markets, Journal of Finance 50, 1719-1734.

Demsetz, Harold, 1968, The cost of transacting, Quarterly Journal of Economics 82, 3353.

Denis, Diane K., John J. McConnell, Alexei V. Ovtchinnikov, and Yun Yu, 2003, S\&P 500 index additions and earnings expectations, Journal of Finance 58, 1821-1840.

D’Mello, Ranjan, Stephen P. Ferris, and Chuan Yang Hwang, 2003, The tax-loss selling hypothesis, market liquidity and price pressure around the turn-of-the-year, Journal of Financial Markets 6, 73-98. 
Ellul, Andrew, Chotibhak Jotikasthira and Christian T. Lundblad, 2009, Regulatory pressure and fire sales in the corporate bond markets, working paper, Indiana University and University of North Carolina

Field, Laura C. and Gordon Hanka, 2001, The expiration of IPO share lockups, Journal of Finance 56, 471-500.

Grossman, Sanford J. and Merton H. Miller, 1987, Liquidity and market structure, Journal of Finance 43, 617-633.

Hand, John R.M., Robert W. Holthausen, and Richard W. Leftwich, 1992, The effect of bond rating agency announcements on bond and stock prices, Journal of Finance 47, 733-752.

Harris, Lawrence and Eitan Gurel, 1986, Price and volume effects associated with changes in the S\&P 500 list; New evidence for the existence of price pressures, Journal of Finance 41, 815-829.

Hong, Gwangheon and Arthur Warga, 2000, An empirical study of bond market transactions, Financial Analysts Journal 56, 32-46.

Hothckiss, Edith and Gergana Jostova, 2007, Determinants of corporate bond trading: A comprehensvie analysis, working paper, Boston College and George Washington University.

Jacoby, Gady, David A. Fowler, and Aron A. Gottesman, 2000, The capital asset pricing model and the liquidity effect: A theoretical approach, Journal of Financial Markets 3, 69-81.

Kaul Aditya, Vikas Mehrotra, and Randall Morck, 2000, Demand curves for stocks do slope down: New evidence from an index weights adjustment, Journal of Finance 55, 893-912.

Keim, Donald B. and Ananth Madhavan, 1998, The cost of institutional equity trades, Financial Analysts Journal 54, 50-69.

Lesmond, David A., Joseph P. Ogden, and Charles A. Trzcinka, 1999, A new estimate of transaction costs, Review of Financial Studies 12, 1113-1141.

Mikkelson, Wayne H. and M. Megan Partch, 1985, Stock price effects and costs of secondary distributions, Journal of Financial Economics 14, 165-194.

Mitchell, Mark, Todd Pulvino and Erik Stafford, 2004, Price pressure around mergers, Journal of Finance 59, 31-63. 
Ofek, Eli and Matthew Richardson, 2000, The IPO lock-up period: Implications for market efficiency and downward sloping demand curves, working paper, New York University.

Sadka, Ronnie, 2006, Momentum and post-earnings-announcement drift anomalies: The role of liquidity risk, Journal of Financial Economics 80, 309-349.

Scholes, Myron S., 1972, The market for securities: Substitution versus price pressure and the effects of information on share price, Journal of Business 45, 179-211.

Schultz, Paul, 2006, Downward Sloping Demand Curves, the Supply of Shares, and the Collapse of Internet Stock Prices, working paper, University of Notre Dame.

Shleifer, Andrei, 1986, Do demand curves for stocks slope down? Journal of Finance 41, 579-590.

Wurgler, Jeffrey and Ekaterina Zhuravskaya, 2002, Does arbitrage flatten demand curves for stocks? Journal of Business 75, 583-608. 


\section{Table I}

\section{Frequency Distribution of Fallen Angel Bonds Based on Number of Transactions} Within 100 Days Before and After the Downgrade Event

This table details the number of buy and sell transactions within 100 days of the downgrade event date for the 1,836 fallen angel bonds identified using the two agency definition (Panel A) and 1,191 fallen angel bonds identified using the four agency definition (Panel B).

Panel A. Fallen Angels Identified Based on Moody's and S\&P

\begin{tabular}{|c|c|c|c|c|}
\hline \multirow[b]{2}{*}{$\begin{array}{l}\text { Number of } \\
\text { Transactions }\end{array}$} & \multicolumn{2}{|c|}{ Buy Transactions } & \multicolumn{2}{|c|}{ Sell Transactions } \\
\hline & $\begin{array}{c}\text { Before } \\
\text { Downgrade }\end{array}$ & $\begin{array}{c}\text { After } \\
\text { Downgrade }\end{array}$ & $\begin{array}{c}\text { Before } \\
\text { Downgrade }\end{array}$ & $\begin{array}{c}\text { After } \\
\text { Downgrade }\end{array}$ \\
\hline 0 & 1176 & 1214 & 891 & 794 \\
\hline 1 & 246 & 239 & 269 & 246 \\
\hline 2 & 108 & 104 & 155 & 179 \\
\hline 3 & 63 & 68 & 97 & 124 \\
\hline 4 & 47 & 49 & 67 & 80 \\
\hline 5 & 36 & 32 & 62 & 64 \\
\hline$(5,10]$ & 91 & 71 & 135 & 184 \\
\hline More than 10 & 69 & 59 & 160 & 165 \\
\hline $\begin{array}{l}\text { Number of Bonds with } \\
\text { Non-Zero Transactions }\end{array}$ & 660 & 622 & 945 & 1042 \\
\hline Total Number of Bonds & 1836 & 1836 & 1836 & 1836 \\
\hline
\end{tabular}

Panel B. Fallen Angels Identified Based on Four Agencies

\begin{tabular}{|c|c|c|c|c|}
\hline \multirow[b]{2}{*}{$\begin{array}{l}\text { Number of } \\
\text { Transactions }\end{array}$} & \multicolumn{2}{|c|}{ Buy Transactions } & \multicolumn{2}{|c|}{ Sell Transactions } \\
\hline & $\begin{array}{c}\text { Before } \\
\text { Downgrade }\end{array}$ & $\begin{array}{c}\text { After } \\
\text { Downgrade }\end{array}$ & $\begin{array}{c}\text { Before } \\
\text { Downgrade }\end{array}$ & $\begin{array}{c}\text { After } \\
\text { Downgrade }\end{array}$ \\
\hline 0 & 745 & 804 & 578 & 505 \\
\hline 1 & 157 & 135 & 167 & 156 \\
\hline 2 & 72 & 65 & 95 & 119 \\
\hline 3 & 43 & 43 & 58 & 82 \\
\hline 4 & 36 & 33 & 48 & 56 \\
\hline 5 & 15 & 24 & 42 & 32 \\
\hline$(5,10]$ & 72 & 52 & 86 & 121 \\
\hline More than 10 & 51 & 35 & 117 & 120 \\
\hline $\begin{array}{l}\text { Number of Bonds with } \\
\text { Non-Zero Transactions }\end{array}$ & 446 & 387 & 613 & 686 \\
\hline Total Number of Bonds & 1191 & 1191 & 1191 & 1191 \\
\hline
\end{tabular}




\section{Table II}

\section{Fallen Angel Bond Returns}

This table reports the cumulative raw and excess (index-adjusted) returns for the fallen angels that have at least one sell transaction on each side of the downgrade date. Average abnormal stock returns are calculated from a market model and t-statistics are based on standard deviations of excess returns during the estimation period [-120,-31]. "Negative Abnormal Stock Return" means the average abnormal stock return for days [-1, 1] is significantly negative at the 5 percent level. In Panels A and B, "Zero Abnormal Stock Return" means the average abnormal stock return for day [-1, 1] is not significantly different from zero at the 5 percent level. In panel C, the "Zero Abnormal Stock Return” category is further restricted such that the average abnormal stock return from the "before_date" to the "after_date” is not significantly different from zero at the 5 percent level. t-statistics are reported in parentheses.

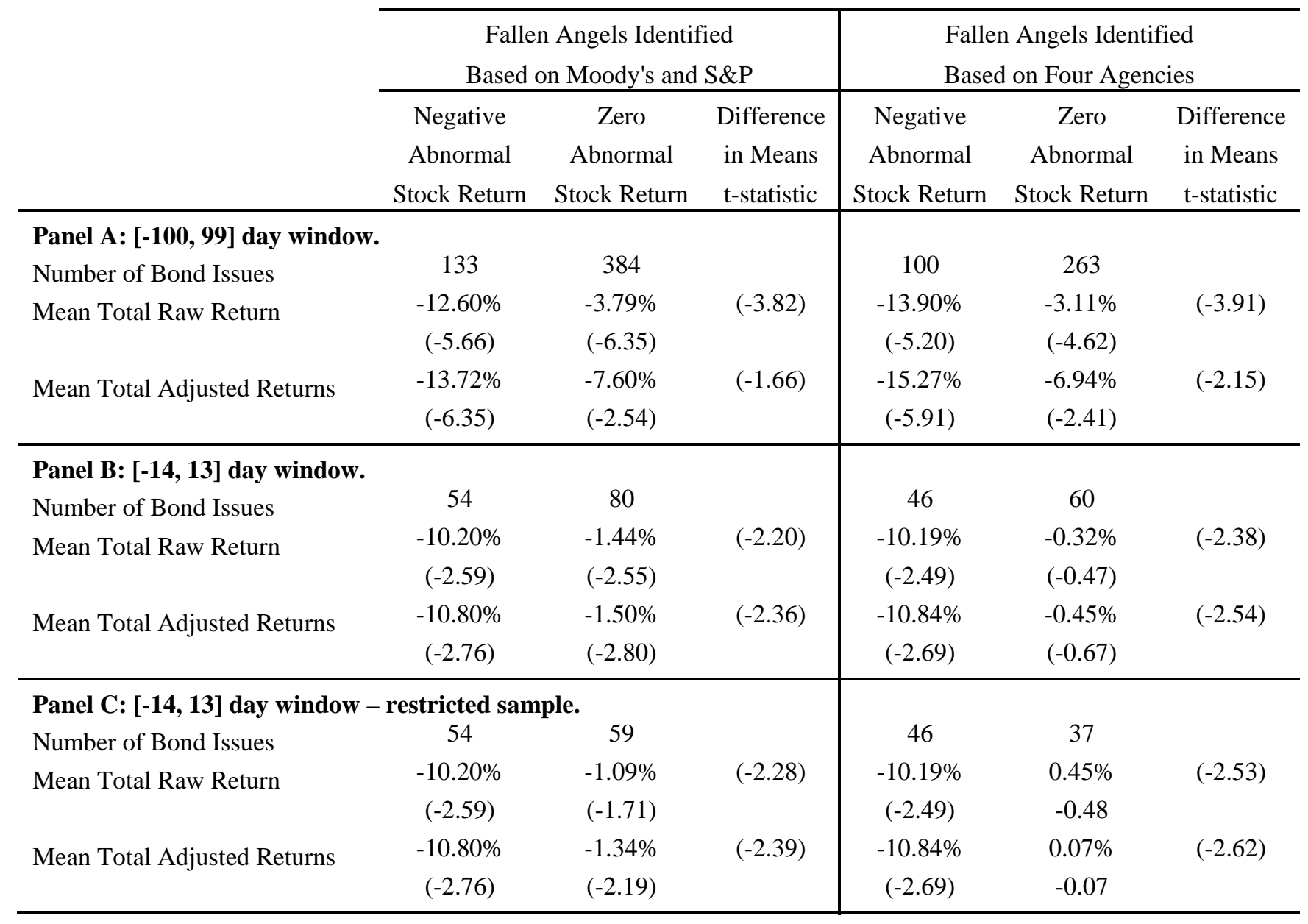




\section{Table III}

\section{Fallen Angel Bond Liquidity Measures}

This table reports summary statistics on liquidity proxies for the bonds in the restricted no-information group and the negative information group that trade within 14 days of the downgrade date. The liquidity measures are calculated for each bond over the window [-120,-31]. Negative Abnormal Stock Return" means the average abnormal stock return for days $[-1,1]$ is significantly negative at the 5 percent level. "Zero Abnormal Stock Return" means the average abnormal stock return for day $[-1,1]$ is not significantly different from zero at the 5 percent level and the average abnormal stock return from the "before_date" to the "after_date" is not significantly different from zero at the 5 percent level. t-statistics are reported in parentheses.

\begin{tabular}{|c|c|c|c|c|c|c|}
\hline & \multicolumn{3}{|c|}{$\begin{array}{c}\text { Fallen Angels Identified } \\
\text { Based on Moody's and S\&P }\end{array}$} & \multicolumn{3}{|c|}{$\begin{array}{l}\text { Fallen Angels Identified } \\
\text { Based on Four Agencies }\end{array}$} \\
\hline & $\begin{array}{c}\text { Negative } \\
\text { Abnormal } \\
\text { Stock } \\
\text { Return } \\
\end{array}$ & $\begin{array}{c}\text { Zero } \\
\text { Abnormal } \\
\text { Stock } \\
\text { Return } \\
\end{array}$ & $\begin{array}{l}\text { Difference } \\
\text { in Means } \\
\text { t-statistic }\end{array}$ & $\begin{array}{c}\text { Negative } \\
\text { Abnormal } \\
\text { Stock } \\
\text { Return } \\
\end{array}$ & $\begin{array}{c}\text { Zero } \\
\text { Abnormal } \\
\text { Stock } \\
\text { Return } \\
\end{array}$ & $\begin{array}{c}\text { Difference } \\
\text { in Means } \\
\text { t-statistic }\end{array}$ \\
\hline Number of Bond Issues & 54 & 59 & & 46 & 37 & \\
\hline Percent of days with zero trading volume & $\begin{array}{l}90.86 \% \\
(66.37)\end{array}$ & $\begin{array}{l}90.04 \% \\
(78.74)\end{array}$ & $(0.46)$ & $\begin{array}{l}89.83 \% \\
(59.81)\end{array}$ & $\begin{array}{l}88.08 \% \\
(59.39)\end{array}$ & $(0.83)$ \\
\hline Total trading volume $(\$ \mathrm{M})$ & $\begin{array}{l}66.26 \\
(4.38)\end{array}$ & $\begin{array}{l}51.50 \\
(5.79)\end{array}$ & $(0.84)$ & $\begin{array}{l}66.19 \\
(3.95)\end{array}$ & $\begin{array}{l}65.85 \\
(5.09)\end{array}$ & $(0.02)$ \\
\hline Total number of trades & $\begin{array}{l}20.24 \\
(5.89)\end{array}$ & $\begin{array}{l}16.83 \\
(7.58)\end{array}$ & $(0.83)$ & $\begin{array}{l}20.43 \\
(5.52)\end{array}$ & $\begin{array}{l}21.43 \\
(6.79)\end{array}$ & $(-0.21)$ \\
\hline Offering Amount (\$M) & $\begin{array}{c}697 \\
(6.21)\end{array}$ & $\begin{array}{c}693 \\
(6.74)\end{array}$ & $(0.03)$ & $\begin{array}{c}738 \\
(5.73)\end{array}$ & $\begin{array}{c}893 \\
(5.88)\end{array}$ & $(-0.78)$ \\
\hline Bond Age at Downgrade (years) & $\begin{array}{c}3.08 \\
(6.93)\end{array}$ & $\begin{array}{c}2.93 \\
(11.50)\end{array}$ & $(0.29)$ & $\begin{array}{c}3.23 \\
(7.71)\end{array}$ & $\begin{array}{c}2.47 \\
(7.33)\end{array}$ & $(1.40)$ \\
\hline Time-to-Maturity (years) & $\begin{array}{l}10.75 \\
(9.89)\end{array}$ & $\begin{array}{l}11.17 \\
(11.25)\end{array}$ & $(-0.29)$ & $\begin{array}{l}11.48 \\
(8.34)\end{array}$ & $\begin{array}{l}11.32 \\
(8.81)\end{array}$ & $(0.08)$ \\
\hline
\end{tabular}




\section{Table IV \\ Liquidity and Bond Returns}

The dependent variable in these OLS regressions is the mean adjusted return $\left(M A R K_{i, n}\right)$ for the no-information, restricted sample. The liquidity measures are calculated for each bond over the window [-120,-31]. t-statistics are reported in parentheses.

\begin{tabular}{|c|c|c|c|c|c|c|}
\hline Panel A: Fallen Angels & Identifie & d Basec & lon Mo & ody's aI & S\&P & $N=59)$ \\
\hline & {$[1]$} & [2] & [3] & {$[4]$} & {$[5]$} & {$[6]$} \\
\hline Intercept & 0.11 & -0.02 & -0.03 & -0.02 & 0.00 & -0.00 \\
\hline & $(1.73)$ & $(-2.72)$ & $(-3.06)$ & $(-2.12)$ & $(0.30)$ & $(-0.05)$ \\
\hline Percent Zero Volume Days & -0.13 & & & & & \\
\hline & $(-1.95)$ & & & & & \\
\hline Total Trading Volume & & 0.01 & & & & \\
\hline & & $(1.57)$ & & & & \\
\hline Total Number of Trades & & & 0.07 & & & \\
\hline & & & $(2.08)$ & & & \\
\hline Offering Amount & & & & 0.58 & & \\
\hline & & & & $(0.74)$ & & \\
\hline Bond Age & & & & & -0.57 & \\
\hline & & & & & $(-1.83)$ & \\
\hline TTM & & & & & & -0.11 \\
\hline & & & & & & $(-1.43)$ \\
\hline R-Square & 0.06 & 0.04 & 0.07 & 0.01 & 0.06 & 0.03 \\
\hline Adjusted R-Square & 0.05 & 0.02 & 0.05 & -0.01 & 0.04 & 0.02 \\
\hline
\end{tabular}

Panel B: Fallen Angels Identified Based on Four Agencies ( $N=37)$

\begin{tabular}{lrrrrrr} 
& \multicolumn{1}{c}{$[1]$} & \multicolumn{1}{c}{$[2]$} & \multicolumn{1}{c}{$[3]$} & \multicolumn{1}{c}{$[4]$} & \multicolumn{1}{c}{$[5]$} & {$[6]$} \\
Intercept & 0.05 & -0.01 & -0.02 & -0.00 & 0.01 & 0.01 \\
& $(0.52)$ & $(-1.01)$ & $(-1.21)$ & $(-0.01)$ & $(0.34)$ & $(0.74)$ \\
Percent Zero Volume Days & -0.06 & & & & & \\
& $(-0.51)$ & & & & & \\
Total Trading Volume & & 0.02 & & & & \\
& & $(1.64)$ & & & & \\
Total Number of Trades & & & 0.09 & & & \\
& & & $(1.68)$ & & & \\
Offering Amount & & & & 0.09 & & \\
& & & & $(0.08)$ & & -0.11 \\
Bond Age & & & & & -0.19 & \\
& & & & & $(-0.39)$ & \\
TTM & & & & & & $(-0.85)$ \\
\hline R-Square & & & & & -0.02 \\
Adjusted R-Square & 0.01 & 0.07 & 0.07 & 0.00 & 0.00 & 0.02 \\
\end{tabular}

